Short communication

\title{
Effect of multi-walled carbon nanotubes on the stability of dye sensitized solar cells
}

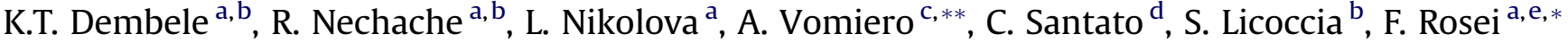 \\ a Institut National de la Recherche Scientifique, Énergie, Matériaux et Télécommunications, 1650 Boul. Lionel-Boulet, Varennes, Québec J3X 1S2, Canada \\ ${ }^{\mathrm{b}}$ Department of Chemical Sciences and Technology \& NAST Center, University of Rome Tor Vergata, Via della Ricerca Scientifica 1, 00133 Rome, Italy \\ ${ }^{c}$ Laboratorio SENSOR, Istituto di Acustica e Sensoristica Orso Mario Corbino, Consiglio Nazionale delle Ricerche, Via Branze 45, 25123 Brescia, Italy \\ ${ }^{\mathrm{d}}$ Département de génie physique, École Polytechnique de Montréal, C.P. 6079, Succ. Centre-ville, Montréal, Québec H3T 1J4, Canada \\ ${ }^{\text {e } C e n t e r ~ f o r ~ S e l f-A s s e m b l e d ~ C h e m i c a l ~ S t r u c t u r e s, ~ M c G i l l ~ U n i v e r s i t y, ~} 801$ Sherbrooke Street West, Montréal, Québec H3A 2K6, Canada
}

\section{H I G H L I G H T S}

- We studied dye sensitized solar cells with and without addition of carbon nanotubes.

- CNTs can improve both photoconversion efficiency and operational stability.

- Optimized CNT loading (0.03\% wt.) maximizes cell performance.

\section{A R T I C L E I N F O}

\section{Article history:}

Received 5 September 2012

Received in revised form

4 January 2013

Accepted 5 January 2013

Available online 22 January 2013

\section{Keywords:}

Dye sensitized solar cells (DSSCs)

Multi-walled carbon nanotubes (MWCNTs)

Power conversion efficiency

Titanium dioxide

DSSC operational stability

\begin{abstract}
A B S T R A C T
We report the improvement of the operational stability of dye-sensitized solar cells (DSSCs) by incorporating multi-wall carbon nanotubes (MWCNTs) in conventional nanostructured semiconducting $\mathrm{TiO}_{2}$ photoanodes. DSSCs were prepared by adding various concentrations of MWCNTs (up to $1.0 \% \mathrm{wt}$.) to $\mathrm{TiO}_{2}$ anatase nanoparticles. Optimization of MWCNT concentration leads to photoconversion efficiency as high as $4.1 \%$ as opposed to $3.7 \%$ for pure $\mathrm{TiO}_{2}$ photoanodes. The performance of the solar cells was measured for 10 consecutive days of continuous ambient light exposure. MWCNT addition results in the decrease of efficiency from $4.1 \%$ to $3.7 \%$, while a decrease from $3.7 \%$ to $2.4 \%$ was recorded in pure $\mathrm{TiO}_{2}$ photoanodes. These results are encouraging toward the commercial exploitation of DSSCs.
\end{abstract}

(c) 2013 Elsevier B.V. All rights reserved.

\section{Introduction}

The rapid depletion of fossil fuels and the escalation in environmental pollution have prompted increased investigations in the field of alternative energy sources [1]. In this context, photovoltaic (PV) cells are being studied to satisfy the increasing power needs of today's society. Driven by advances in technology, power conversion efficiencies of about $25 \%$ have been reached for Si single crystalbased PV cells [2] and of $41 \%$ for triple-junction GaInP/GaInAs/Gebased cells under 364 times concentrated sunlight [3]. However, the

\footnotetext{
* Corresponding author. INRS-EMT, 1650 Boul. Lionel-Boulet, Varennes, Québec J3X 1S2, Canada. Tel.: +1 (514) 228 6906; fax: +1 (450) 9298102.

** Corresponding author. CNR, IDASC, SENSOR Lab, Via Branze 45, 25123 Brescia, Italy.

E-mail addresses: alberto.vomiero@ing.unibs.it (A. Vomiero), rosei@emt.inrs.ca (F. Rosei).
}

performance of these cells is still lower than the predicted values. Moreover, they make use of expensive materials and they employ complicated and costly processing steps. A potentially inexpensive alternative is represented by dye-sensitized solar cells (DSSCs), firstly introduced by O'Regan and Grätzel in 1991 [4].

A typical DSSC makes use of a photoanode based on a porous layer of semiconducting titanium dioxide $\left(\mathrm{TiO}_{2}\right)$ nanoparticles, photosensitized by a dye (e.g. a ruthenium polypyridyl complex), deposited on a conductive glass substrate. After sunlight absorption, the photo-generated electron in the dye is transferred to the conduction band of the $\mathrm{TiO}_{2}$ where it moves toward the back contact to finally enter the circuit. The dye is then regenerated from its oxidized form by electron transfer from iodide ions $\left(\mathrm{I}^{-}\right)$dissolved in the electrolyte that permeates the porous $\mathrm{TiO}_{2}$ nanoparticles structure. The tri-iodide ions $\left(\mathrm{I}_{3}{ }^{-}\right)$formed in the dye regeneration process diffuse through the liquid electrolyte to the cathode, where they are reduced back to $\mathrm{I}^{-}$, to complete the cycle. 
Optimized DSSCs have reached a considerable solar-to-electrical power conversion efficiency of $12.3 \%$ at AM $1.5 \mathrm{G}$ [5]. This efficiency, while currently limited to laboratory prototypes, is promising when compared to the 13-25\% efficiency observed for Si PV cells, thus opening the opportunity to effectively exploit the DSSC technology [6]. However, several challenges still exist, e.g. related to the performance stability of the cells operated for prolonged irradiation times.

Rapid recombination of photo-generated charge carriers limits the efficiency of DSSCs [7]. Alternative materials or/and structures able to improve DSSCs performance and their stability without affecting the overall cost are a critical issue to make DSSC commercially viable [8-12].

A few recent papers demonstrated that the use of carbon nanotubes (CNTs) can improve DSSC performance [13-18]. CNTs have been successfully applied as counter-electrodes to decrease the charge transfer resistance $[13,17,19]$, in conjunction with $\mathrm{TiO}_{2}$ hollow spheres, to simultaneously obtain fast electron transport and enhanced light scattering at the photoanode [15] or conformal coating by $\mathrm{TiO}_{2}$ nanoparticles to create preferential channels for charge collection. There are two types of CNTs, multi-walled carbon nanotubes (MWCNTs) that are mainly conducting and single walled CNTs (SWCNTs) that can be semiconducting or conducting [19]. Previous studies have shown that $\mathrm{TiO}_{2}-$ CNTs heterojunctions may inhibit the recombination of photogenerated charge carriers $[20,21]$. Moreover, adding MWCNTs to $\mathrm{TiO}_{2}$ nanoparticles improves the dispersion of the nanoparticles in solution, promoting the formation of a porous structure in the $\mathrm{TiO}_{2}$ layer, in turn leading to a higher surface area for efficient dye adsorption [22-24]. While improved photoconversion efficiency has been demonstrated by addition of CNTs to conventional photoanodes, an investigation of the stability of the photoelectrochemical system is still lacking, and this is critical for the practical exploitation of the DSSC technology $[25,26]$.

In this work, we report on comparative studies carried out on DSSCs based on $\mathrm{TiO}_{2}$ photoanodes before and after addition of different amounts of MWCNTs to $\mathrm{TiO}_{2}$. At the optimal MWCNT concentration, we demonstrate improved performance and operational stability of DSSCs.

\section{Experimental}

\subsection{Materials}

Anatase $\mathrm{TiO}_{2}$ nanopowder (purity 99\%, $20 \mathrm{~nm}$ diameter, Sigma Aldrich) and commercial MWCNTs (purity >95\%, $20 \mathrm{~nm}$ diameter, Sigma Aldrich) were employed to prepare the $\mathrm{TiO}_{2}$ layer and the $\mathrm{TiO}_{2}-\mathrm{MWCNT}$ composite layer. For the electrolyte, $\mathrm{I}_{2}$, LiI, and acetonitrile (Sigma Aldrich) were used as received. DSSCs (active area of $0.25 \mathrm{~cm}^{2}$ ) were fabricated on Fluorine-doped Tin Oxide (FTO)-coated glass substrates and sensitized with a N719 dye (Sigma Aldrich).

\section{2. $\mathrm{TiO}_{2}$ and $\mathrm{TiO}_{2}-M W C N T$ s photo-anode preparation and characterization}

The $\mathrm{TiO}_{2}$ paste was prepared by dispersing the $\mathrm{TiO}_{2}$ nanopowder in ethanol. The $\mathrm{TiO}_{2}-\mathrm{MWCNT}$ composite paste was prepared by mixing various concentrations of MWCNT (in the range $0.03-1.00 \%$ wt.) with the $\mathrm{TiO}_{2}$ nanopowder, dispersing the mixture in ethanol. Both pastes were treated in an ultrasonic bath for $1 \mathrm{~h}$ and then stirred for $30 \mathrm{~min}$. The pastes were then printed on the FTO coated glass by using the doctor blade method and the samples were annealed at $450{ }^{\circ} \mathrm{C}$ for $30 \mathrm{~min}[4,27]$.

The morphology and structure of $\mathrm{TiO}_{2}$ and $\mathrm{TiO}_{2}-\mathrm{MWCNT}$ layers were investigated by scanning electron microscopy (SEM,JEOL 7401F) and transmission electron microscopy (TEM, Philips CM200 $200 \mathrm{kV}$ ).

\subsection{Photoanode sensitization and DSSC preparation and characterization}

$\mathrm{TiO}_{2}$ and $\mathrm{MWCNT}-\mathrm{TiO}_{2}$ layers were sensitized by a 20 hour-long impregnation in $5 \cdot 10^{-4} \mathrm{M}$ ethanol solution of commercial N719 dye. Afterward, the layers were washed with ethanol to remove the excess dye. A hole drilled on the counter electrode (platinized FTO glass) was used to enable the injection of the electrolyte after cell assembling. Anode and cathode were sealed together using a thermoplastic mask (Surlyn, $60 \mu \mathrm{m}$-thick, melting temperature $100{ }^{\circ} \mathrm{C}$, with a hole of $0.36 \mathrm{~cm}^{2}$ ) and a thermal press. The assembled DSSC was filled with the electrolyte, under vacuum, using the counter electrode hole. Two series of DSSCs, making use of $\mathrm{TiO}_{2}$ and $\mathrm{TiO}_{2}-$ MWCNTs layers, were prepared.

In the following, we discuss the results related to the cells with best performance for each series (at least three cells were prepared for each MWCNT concentration), which are representative of the general trends of the two series of photoanodes.

\section{Results and discussion}

SEM images of the $\mathrm{TiO}_{2}$ nanoparticle layers show a complete coverage of the substrate (Fig. 1a). Typically, low concentrations of MWCNTs incorporated into $\mathrm{TiO}_{2}$ are not visible by SEM imaging
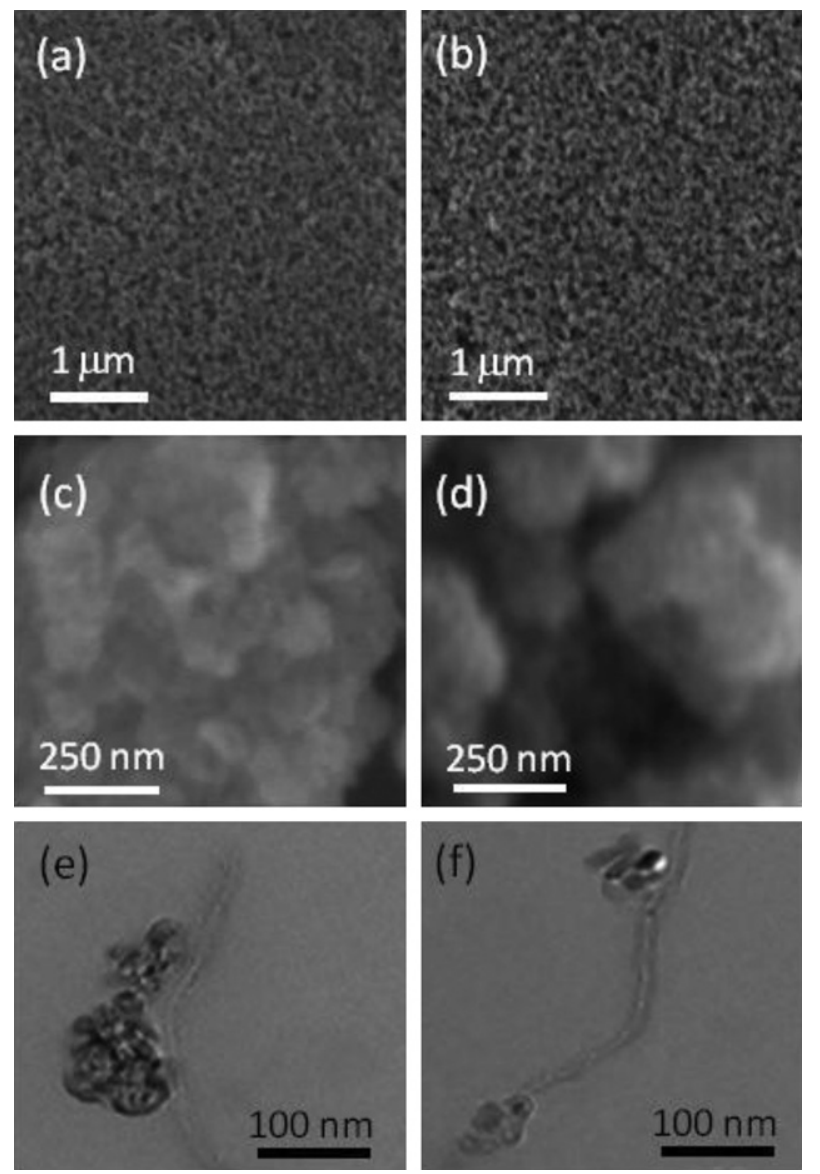

Fig. 1. SEM image at $10 \mathrm{kV}$ of $\mathrm{TiO}_{2}$ nanoparticle layer prepared in this work (a) without MWCNTs and (b) with $0.03 \%$ wt. MWCNTs; high magnification SEM image of $\mathrm{TiO}_{2}$ nanoparticles (c) without MWCNTs and (d) 1.0\% wt. MWCNTs. (e) TEM bright field image of $\mathrm{TiO}_{2}$ agglomerates of nanoparticles connected to a MWCNT and (f) TEM bright field image of $\mathrm{TiO}_{2}$ agglomerates associated to different sites of a MWCNT. Samples (e) and (f) make use of the same ratio of MWCNTs/TiO 2 (0.03\% wt. of MWCNTs) and the TEM images were made at $200 \mathrm{kV}$. 


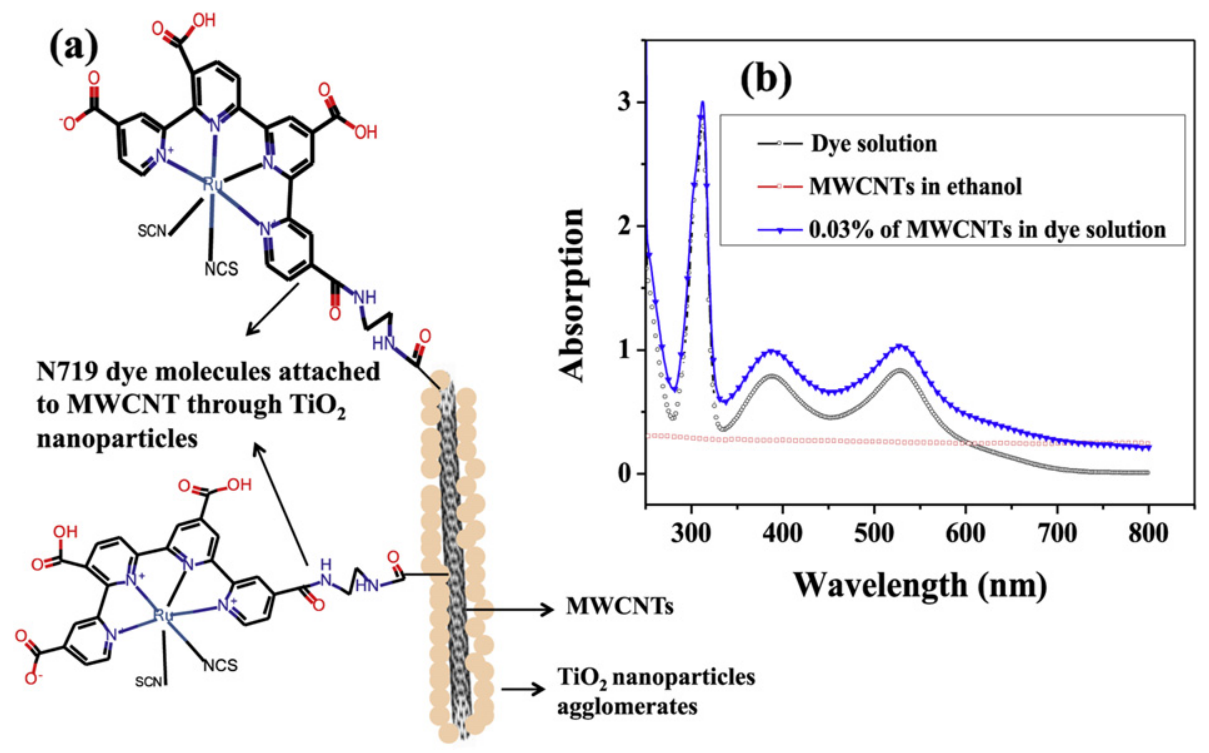


ethanol solution, MWCNTs dispersed in ethanol solution and $0.03 \%$ wt. MWCNTs dispersed in N719 dye solution.

[28]. TEM investigation on selected MWCNTs partially covered by $\mathrm{TiO}_{2}$ aggregates indicates that simple or multiple connections of aggregates of $\mathrm{TiO}_{2}$ nanoparticles to MWCNTs are possible (Fig. 1e and $\mathrm{f}$ ). TEM images suggest a good affinity between the $\mathrm{TiO}_{2}$ and the MWCNTs, which is important in view of limiting the MWCNT loading required to improve DSSC performance. MWCNTs improve the roughness factor of the electrode and limit the charge recombination of electron/hole $\left(\mathrm{e}^{-} / \mathrm{h}^{+}\right)$pairs [26]. Nevertheless, a high loading of MWCNTs causes light-harvesting competition that affects the light absorption of the dye-sensitizer and consequently reduces the cell efficiency. Moreover, excess of MWCNTs can result in a less compact $\mathrm{TiO}_{2}$ layer, in which large pores form at the micron scale [28] or in the formation of quite disconnected aggregates of MWCNTs covered in conformance by $\mathrm{TiO}_{2}$ nanoparticles (see Fig. $1 \mathrm{~d}$, sample $1.00 \% \mathrm{wt}$.).

Initially, we investigated the effect of the presence of MWCNTs on the optical absorption properties of the dye to identify potential detrimental effects on the DSSC performance. In this context, the literature suggests the existence of connections between MWCNTs and N719 dye molecules $[29,30]$ such that the connection between the $\mathrm{TiO}_{2}-$ MWCNTs composite and the N719 dye molecules could be sketched as in Fig. 2a.

UV-visible absorption spectra were obtained from three samples: N719 dye in ethanol solution, MWCNTs dispersed in ethanol, and MWCNTs dispersed in the dye/ethanol solution (Fig. 2b). N719 dye exhibits the typical three-peak absorption fingerprint, while MWCNTs show an almost constant absorption in the range $300-800 \mathrm{~nm}$. The addition of MWCNTs in dye solution results in a slight and homogeneous enhancement of the absorbance in the UV-visible range, without any significant modification of the absorption features (peak position and relative intensity) that would suggest an interaction between the MWCNTs and the dye.

Fig. 3b displays the current density-voltage $(J-V)$ curves of cells fabricated with different MWCNT concentrations under AM 1.5C irradiation. The device characteristics of these cells are reported in Fig. 4. The best characteristics are found in the sample containing $0.03 \%$ wt. MWCNTs. At higher MWCNT concentrations, according to literature [28] and to our findings on the morphology of the $1.00 \%$ wt. composite system (see the comparison between Fig. 1c and d)
MWCNT addition induces the formation of cracks and holes in the compact structure of the $\mathrm{TiO}_{2}$ thick film, which results less compact than the $\mathrm{TiO}_{2}$ layer without MWCNT addition in terms of close packing of $\mathrm{TiO}_{2}$ nanoparticles.

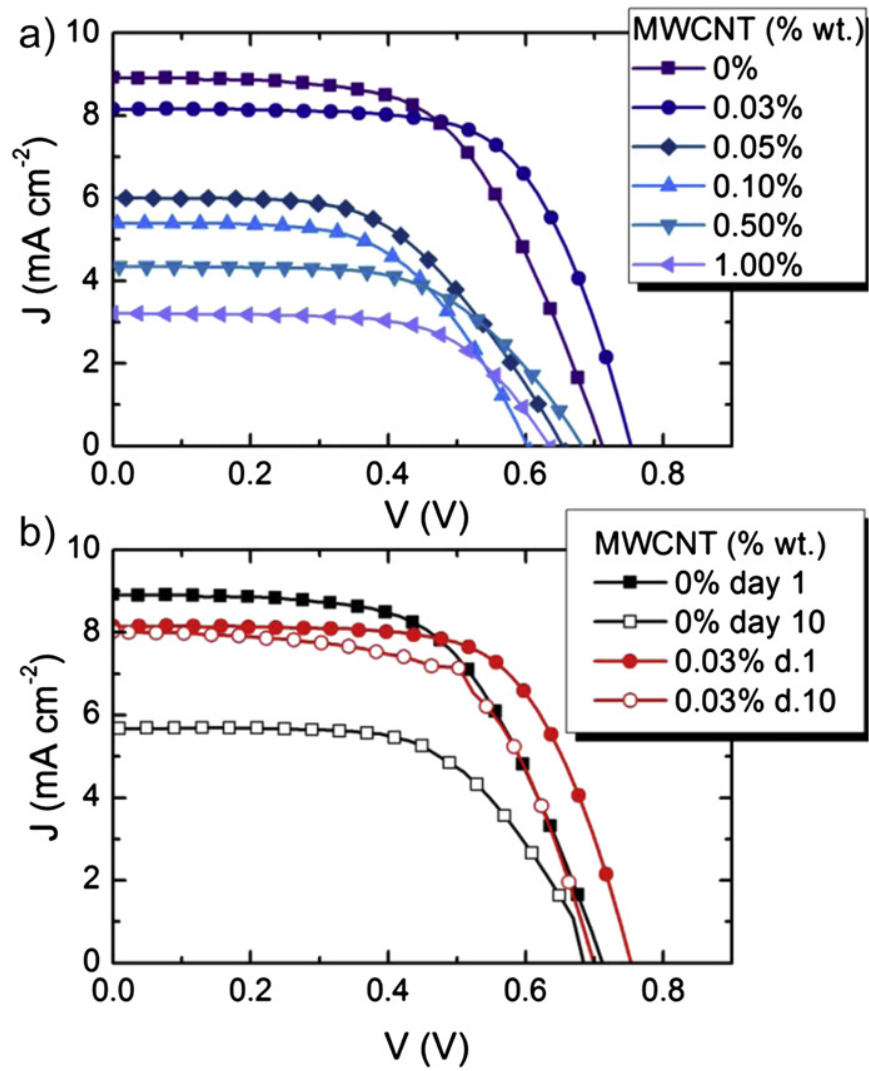

Fig. 3. (a) $J-V$ curves for solar cells with different MWCNT concentrations, from $0 \%$ wt. to $1.0 \%$ wt under AM $1.5 \mathrm{G}$ simulated solar light irradiation. (b) $J-V$ curves for freshly prepared DSSCs and for DSSCs after 10 days of irradiation. DSSCs made with conventional $\mathrm{TiO}_{2}$ photoanodes versus $\mathrm{TiO}_{2}-$ MWCNTs photoanodes are tested and compared under AM $1.5 \mathrm{G}$ simulated solar lights. 


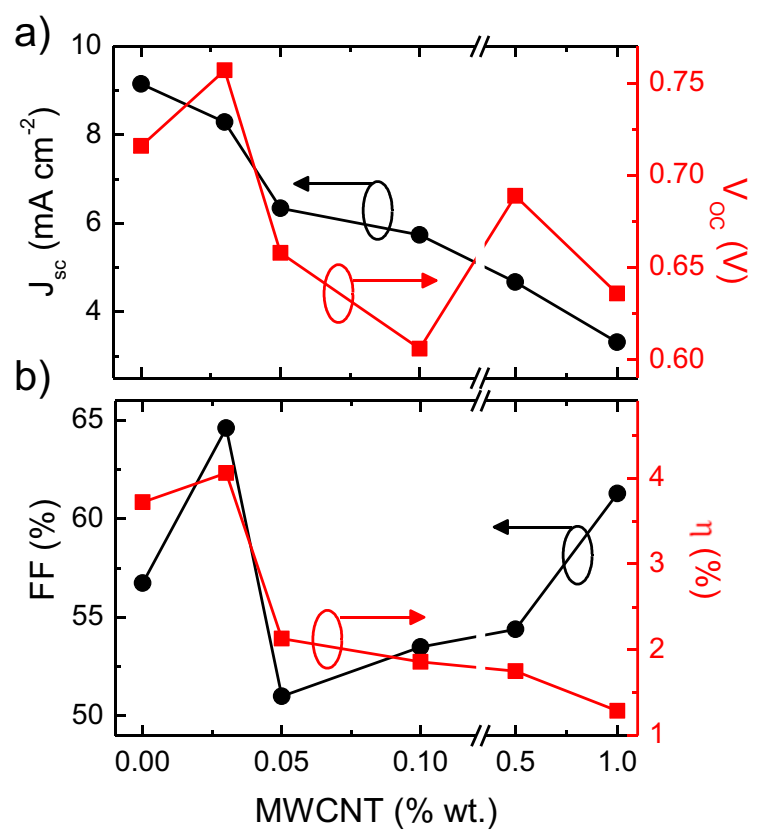

Fig. 4. Functional properties of the solar cells reported in Fig. 3a as a function of the MWCNT content. (a) $J_{\mathrm{sc}}$ and $V_{\mathrm{oc}}$, (b) FF, and $\eta$.

The $J-V$ curves obtained for freshly prepared DSSCs and for DSSCs after 10 consecutive days of continuous ambient light irradiation are illustrated in Fig. 3b. DSSCs with $\mathrm{MWCNT}-\mathrm{TiO}_{2}$ photoanodes exhibit a short circuit photocurrent density, $J_{s c}$, and an open circuit voltage, $V_{\mathrm{oc}}$, of $8.30 \mathrm{~mA} \mathrm{~cm}^{-2}$ and $0.76 \mathrm{~V}$, respectively, while these values are $9.15 \mathrm{~mA} \mathrm{~cm}{ }^{-2}$ and $0.72 \mathrm{~V}$ for conventional DSSCs, based on $\mathrm{TiO}_{2}$ photoanodes.

The power conversion efficiency, $\eta$, was estimated as $\eta=P_{\text {out }}^{\max } / P_{\text {in }}$, where $P_{\text {out }}^{\max }=J_{\max } \cdot V_{\max }$ is the maximum output electrical power density, $J_{\max }$ and $V_{\max }$ are the photocurrent density and photovoltage generated by the cells at the peak power, respectively, and $P_{\text {in }}\left(100 \mathrm{~mW} \mathrm{~cm}^{-2}\right)$ is the power density of the AM 1.5G simulated solar light. The best power conversion efficiency was found to be $4.1 \%$ for DSSCs making use of MWCNTs and $3.7 \%$ for conventional DSSCs. The moderate increase of the performance is mainly due to the increased fill factor (FF, which is the ratio of maximum obtainable power to the product of the open-circuit voltage and short-circuit current) in the optimized solar cell $(64 \%$ with respect to $53 \%$ in pure $\mathrm{TiO}_{2}$ photoanode) and $V_{\mathrm{oc}}(0.76 \mathrm{~V}$ as compared to $0.72 \mathrm{~V}$ ), both ascribed to the improved charge collection. The photocurrent density is negatively affected by the addition of MWCNTs, due to their competitive light absorption (Fig. 2), which causes partial loss of visible radiation. Such circumstance does not allow improving the photoconversion efficiency as much as reported in Ref. [26], where the large increase of photoconversion efficiency was related to a $48 \%$ enhancement of $J_{s c}$. In particular, in Ref. [26], the enhanced $J_{s c}$ is mainly ascribed to the reduced crystallite size induced by the presence of MWCNTs during the synthesis of $\mathrm{TiO}_{2}$ nanoparticles through sol-gel, and consequent enhancement of the roughness factor (i.e. the total surface area per unit substrate area). Here instead, the size of $\mathrm{TiO}_{2}$ nanoparticles is the same for all the samples, since MWCNTs are added to nanoparticles after their synthesis, so the beneficial effect of size reduction cannot be exploited.

The presence of MWCNTs is also expected to increase $V_{\text {oc }}$ in DSSCs including $\mathrm{Li}^{+}$in the electrolyte. In DSSCs, $\mathrm{Li}^{+}$is usually added to enhance $J_{s c}$ [31-35]. $\mathrm{Li}^{+}$can occupy different sites of the MWCNT surface and/or can be positioned inside an individual nanotube, through end-cap or sidewall openings. Moreover, $\mathrm{Li}^{+}$intercalation can occur in the MWCNT (through lattice defects or open nanotube ends) [36-38]. As a consequence, the concentration of $\mathrm{Li}^{+}$within the $\mathrm{TiO}_{2}$ layer decreases in the presence of MWCNTs, thus limiting the detrimental effect of $\mathrm{Li}^{+}$on the location of the $\mathrm{TiO}_{2}$ conduction band edge $\left(\mathrm{Li}^{+}\right.$causes a shift in the band edges toward more positive values), thus improving $V_{\mathrm{oc}}$. This observation is in agreement with $V_{\text {oc }}$ values obtained for DSSCs with $\mathrm{TiO}_{2}-$ MWCNTs photoanodes. The positive effect of MWCNTs on $V_{\text {oc }}$ and FF largely compensates their detrimental effect on $J_{s c}$, ensuring an overall improvement of the power photoconversion efficiency $(\eta)$ of the cells.
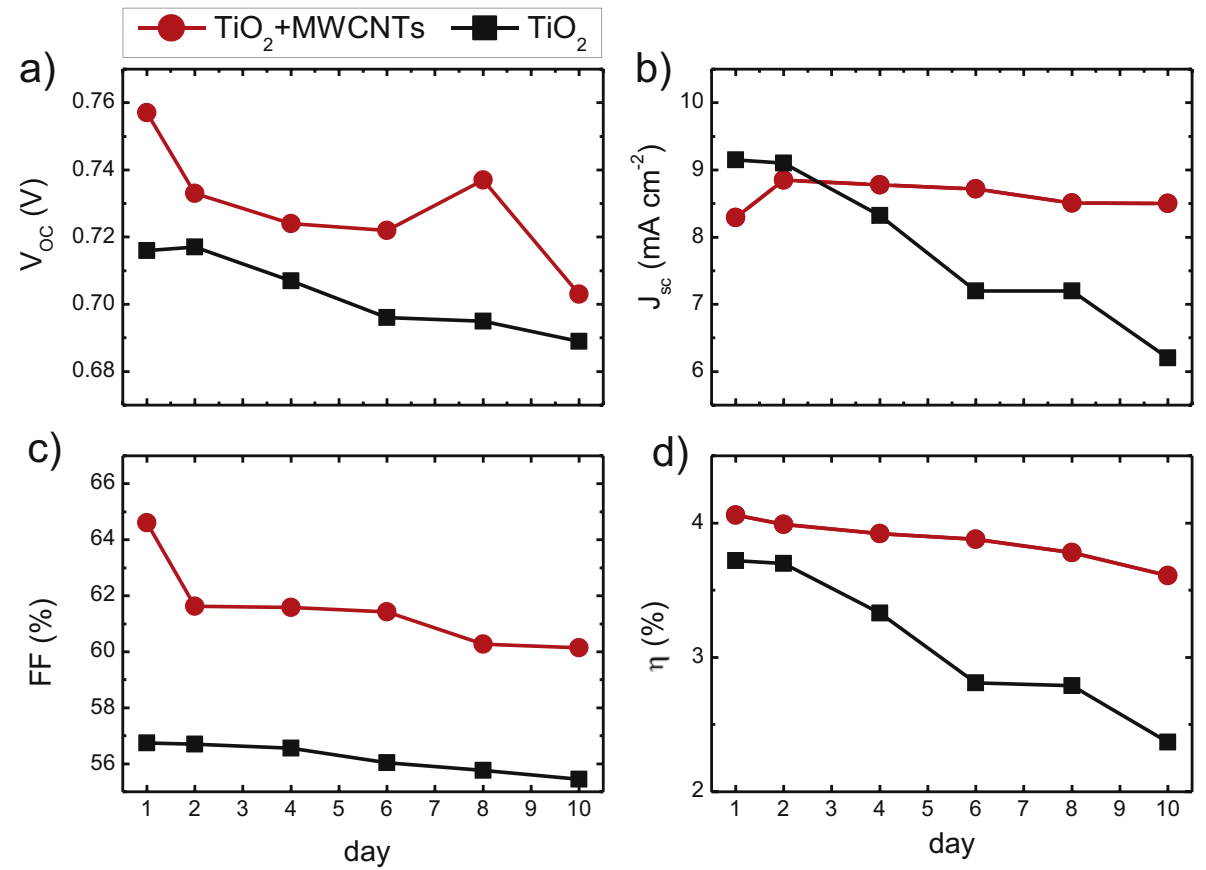




To study the effect of MWCNTs addition on DSSCs performance over time, the cells were tested for a period of 10 consecutive days under continuous ambient light. Fig. 5 illustrates the time evolution of the figures of merit of the best cells of the two series (this evolution being representative of the general trend of the two series of devices we investigated).

The results indicate that adding MWCNTs significantly improves cell performance, mainly by stabilizing the $J_{\mathrm{sc}}$ (see Fig. $5 \mathrm{~b}$ ). As displayed in Fig. 5d, the efficiency of conventional DSSCs (i.e. without MWCNTs) rapidly decreases with time, from 3.7 to $2.3 \%$ after 10 days, mainly due to the strong decrease of $J_{s c}$.

A first hypothesis to explain the improved performance stability of DSSCs making use of MWCNTs could be the formation of MWCNTs-based conducting networks inside the photoanode, which limits the recombination of the photo-produced charge carriers. However, recent experimental findings highlight that the limited long-term stability of N719 dye is the main cause for the degradation of N719-based DSSCs [26]. In this respect, the effect of MWCNTs on cell stabilization and their possible interaction with N719 dye is still unclear. Further investigations are planned to gain new insight on the factors that contribute to improve DSSC stability.

\section{Conclusions and perspectives}

In summary, the addition of MWCNTs to $\mathrm{TiO}_{2}$ nanostructured photoanodes increases the power conversion efficiency and the operational stability of the DSSCs. The low loading of MWCNTs limits light-harvesting competition between the dye-sensitizer and the MWCNTs, which would be detrimental for the power conversion efficiency of the operating device. At present, other semiconducting materials such as $\mathrm{ZnO}$ and $\mathrm{TiO}_{2}$ nanohole $[39,40]$ are under investigation to test the general validity of our approach to improve the overall operational stability of DSSC.

\section{Acknowledgments}

We acknowledge financial support from the Canada Foundation for Innovation, NSERC Discovery grant (F.R. and C.S.), MDEIE (international collaboration grant with EU Network WIROX), and FQRNT (team grant). F.R. is grateful to the Canada Research Chairs Program for partial salary support. K.T.D. and R.N. are grateful to the joint laboratory on Advanced Materials for Energy, Environment and Health, University of Rome Tor Vergata and INRS-EMT for partial salary support. R.N. acknowledges a personal postdoctoral fellowship from NSERC. The authors thank professor A. Di Carlo and F. Matteocci at CHOSE (Center of Hybrid Organic Solar Cells) at University of Rome Tor Vergata for access to equipment for DSSCs fabrication. A.V. acknowledges the European Union for partial funding under the contract $\mathrm{N}^{\circ}$ 299490, F-Light, Marie Curie International Outgoing Fellowship, and under the contract $\mathrm{N}^{\circ}$ 295216, WIROX, Marie Curie Actions-International Research Staff Exchange Scheme (IRSES). L.N. is grateful to NSERC and FRQNT for CGS Alexander Graham Bell and BDR personal fellowships, respectively.

\section{References}

[1] J. Nelson, The Physics of Solar Cells, Imperial College Press, London, 2003.

[2] M.A. Green, Prog. Photovolt. Res. Appl. 17 (2009) 183-189.

[3] M.A. Green, K. Emery, Y. Hishikawa, W. Warta, Prog. Photovolt. Res. Appl. 18 (2010) 144-150.

[4] B. O’Regan, M. Grätzel, Nature 353 (1991) 737-740.

[5] N. Fuke, A. Fukui, A. Islam, R. Komiya, R. Yamanaka, H. Harima, L. Han, Sol Energy Mater. Sol. Cells 93 (2009) 720-724.

[6] A. Yella, H.-W. Lee, H.N. Tsao, C. Yi, A.K. Chandiran, M.K. Nazeeruddin, E.W.-G. Diau, C.-Y. Yeh, S.M. Zakeeruddin, M. Grätzel, Science 334 (2011) 629-634.

[7] M.A. Green, K. Emery, Y. Hishikawa, W. Warta, Prog. Photovolt. Res. Appl. 19 (2011) 84-92.

[8] T. Berger, M. Sterrer, O. Diwald, J. Phys. Chem. B 109 (2005) 6061-6068.

[9] Z.S. Wang, T. Yamaguchi, H. Sigihara, H. Arakawa, Langmuir 21 (2005) 4272-4276.

[10] K.H. Ko, Y.C. Lee, YJ. Jung, J. Colloid Interface Sci. 283 (2005) 482-487.

[11] G.R.A. Kumara, S. Kaneko, A. Konno, M. Okuya, K. Murakami, Prog. Photovolt. Res. Appl. 14 (2006) 643-651.

[12] M. Berginc, U.O. Krašovec, M. Jankovec, M. Topic, Sol. Energy Mater. Sol. Cells 91 (2007) 821-828.

[13] Y. Satio, T. Kitamura, Y. Wada, S. Yanagida, Chem. Lett. 31 (2002) 1060-1061.

[14] T. Sawatsuk, A. Chindaduang, C. Sae-Kung, S. Pratontep, G. Tumcharern, Diam. Relat. Mater. 18 (2009) 524-527.

[15] J. Yu, J. Fan, B. Cheng, J. Power Sources 196 (2011) 7891-7898.

[16] T.Y. Lee, P.S. Alegaonkar, J.B. Yoo, Thin Solid Films 515 (2007) 5131-5135.

[17] S. Pimanpang, W. Maiaugree, W. Jarernboon, S. Maensiri, V. Amornkitbamrung, Synth. Met. 159 (2009) 1996-2000.

[18] H.Zhu, J. Wei, K. Wang, D. Wu, Sol. Energy Mater. Sol. Cells 93 (2009) 1461-1470.

[19] E. Ramasamy, W.J. Lee, D.Y. Lee, J.S. Song, Electrochem. Commun. 10 (2008) 1087-1089.

[20] Y. Zhang, T. Ichihashi, E. Landree, F. Nihey, S. Iijima, Science 285 (1999) 1719-1722.

[21] A. Kongkanand, R.M. Domìnguez, P.V. Kamat, Nano Lett. 7 (2007) 676-680.

[22] E. Bekyarova, E.T. Thostenson, A. Yu, H. Kim, J. Gao, J. Tang, H.T. Hahn, T.-W. Chou, M.E. Itkis, R.C. Haddon, Langmuir 23 (2007) 3970-3974.

[23] A. Jitianu, T. Cacciaguerra, R. Benoit, S. Delpeux, F. Béguin, S. Bonnamy, Carbon 42 (2004) 1147-1151.

[24] X. Li, J. Niu, J. Zhang, H. Li, Z. Liu, J. Phys. Chem. B 107 (2003) 2453-2458.

[25] M. Gratzel, C. R. Chim. 9 (2006) 578-583.

[26] G. Xue, Y. Guo, T. Yu, J. Guan, X. Yu, J. Zhang, J. Liu, Z. Zou, Int. J. Electrochem. Sci. 7 (2012) 1496-1511.

[27] B.K. Koo, D.Y. Lee, H.J. Kim, W.J. Lee, J.S. Song, H.J. Kim, J. Electroceram. 17 (2006) 79-82.

[28] C.-Y. Yen, Y.-F. Lin, S.-H. Liao, C.-C. Weng, C.-C. Huang, Y.-H. Hsiao, C.-C.M. Ma, M.-C. Chang, H. Shao, M.-C. Tsai, C.-K. Hsieh, C.-H. Tsai, F.-B. Weng, Nanotechnology 19 (2008) 375305-375313.

[29] M. Grätzel, J. Photochem. Photobiol. C 4 (2003) 145-153.

[30] J. Yu, S. Mathew, B.S. Flavel, M.R. Johnston, J.G. Shapter, J. Am. Chem. Soc. 130 (2008) 8788-8796.

[31] R. Martin, L. Jiménez, M. Alvaro, J.C. Scaiano, H. Garcia, Chem. Eur. J. 16 (2010) $7282-7292$.

[32] S. Nakade, T. Kanzaki, W. Kubo, T. Kitamura, Y. Wada, S. Yanagida, J. Phys. Chem. B 109 (2005) 3480-3487.

[33] S. Kambe, S. Nakade, T. Kitamura, Y. Wada, S. Yanagida, J. Phys. Chem. B 106 (2002) 2967-2972.

[34] C.A. Kelly, F. Farzad, D.W. Thompson, G.J. Meyer, Langmuir 15 (1999) 731-737.

[35] T.N. Murakami, S. Ito, Q. Wang, Md.K. Nazeeruddin, T. Bessho, I. Cesar, P. Lisk R. Humphry-Baker, P. Comte, P. Péchy, M. Grätzel, J. Electrochem. Soc. 153 (2006) A2255-A2261.

[36] S.H. Seo, S.Y. Kim, B.-K. Koo, S.-Ii. Cha, D.Y. Lee, Langmuir 26 (2010) 10341-10346.

[37] B. Song, J. Yang, J. Zhao, H. Fang, Energy Environ. Sci. 4 (2011) 1379-1384.

[38] B.J. Landi, M.J. Ganter, C.D. Cress, R.A. Di Leo, R.P. Raffaelle, Energy Environ. Sci. 2 (2009) 638-654.

[39] H. Masuda, K. Fukuda, Science 268 (1995) 1466-1468.

[40] H. Nanjo, F.M.B. Hassan, S. Venkatachalam, N. Teshima, K. Kawasaki, T. Aizawa, T. Aida, T. Ebina, J. Power Sources 195 (2010) 5902-5908. 